\title{
Single-center evaluation of prognostic factors for thymoma treated by surgery: a retrospective study
}

\author{
Satoshi Kamata* ${ }^{*}$, Itaru Ishida, Yuyo Suzuki and Hiroyuki Oura
}

\begin{abstract}
Background: This study aimed to retrospectively evaluate the clinical, pathological, and treatment-related factors associated with survival in patients with surgically treated thymomas.

Methods: Sixty patients with thymomas who underwent treatment at our institution between 2004 and 2015 were included. Survival analysis was performed based on curves that were obtained using the Kaplan-Meier method. The Wilcoxon test was used for all comparisons, and $p<0.05$ was considered statistically significant.

Results: Forty-seven, four, three, four, and two patients presented tumor stages I, II, III, IVa, and IVb (according to the Masaoka classification), respectively, while six, 14, 11, 22, and seven patients had type $A, A B, B 1, B 2$, and $B 3$ thymomas, respectively. Furthermore, 53 and eight patients underwent complete resection and required additional resection of adjacent organs, respectively, and no patients died from surgery-related complications. The five-year survival and recurrence-free survival (RFS) rates were 96 and 86\%, respectively. The five-year survival rate for all stages was 100\% except for those with stage IVb tumors (Masaoka classification); the survival rate for those patients was 0\%. Separately, the five-year RFS rates for tumor stages I, II, III, IVa, and IVb were 100, 91, 91, 81, and 71\%, respectively. Finally, the five-year survival rates in cases with complete and incomplete resections were 100 and $71 \%$, respectively, indicating that the latter group had a significantly poorer prognosis $(p<0.001)$.

Conclusions: These findings suggest that complete resection and the Masaoka pathological stage are significant predictors of prognosis in patients with thymomas. Surgery should aim to achieve complete resection; however, advanced cases may require multimodality therapy.
\end{abstract}

Keywords: Thymoma, Complete resection, Masaoka pathological stage, Postoperative recurrence, Five-year survival

\section{Background}

Thymomas are thymic epithelial neoplasms that are often treated using complete resection. However, according to the World Health Organization (WHO) classification and advanced tumors of stages III and IV of the Masaoka staging system, postoperative recurrence is observed in histologically highly malignant cases, such as types B2 and B3 thymomas. This study aimed to

\footnotetext{
* Correspondence: a2m1035j@yahoo.co.jp

Iwate Prefectural Central Hospital, Department of Thoracic Surgery, Ueda 1-4-1, Morioka 020-0066, Japan
}

(c) The Author(s). 2021 Open Access This article is licensed under a Creative Commons Attribution 4.0 International License, which permits use, sharing, adaptation, distribution and reproduction in any medium or format, as long as you give appropriate credit to the original author(s) and the source, provide a link to the Creative Commons licence, and indicate if changes were made. The images or other third party material in this article are included in the article's Creative Commons licence, unless indicated otherwise in a credit line to the material. If material is not included in the article's Creative Commons licence and your intended use is not permitted by statutory regulation or exceeds the permitted use, you will need to obtain permission directly from the copyright holder. To view a copy of this licence, visit http://creativecommons.org/licenses/by/4.0/ The Creative Commons Public Domain Dedication waiver (http://creativecommons.org/publicdomain/zero/1.0/) applies to the data made available in this article, unless otherwise stated in a credit line to the data. 
board of our hospital. The requirement for individual patient consent was waived because only routine patient data were used to conduct this retrospective analysis.

\section{Study design and follow-up}

The disease stage was determined using the MasaokaKoga Stage Classification System for Thymic Epithelial Tumors, and the Tumor, Node, Metastasis Classification, eighth edition. All surgical specimens were reviewed by pathologists and categorized using the WHO classification system.

After the surgery, the patients underwent postoperative follow-up examinations, such as chest X-ray three times a year and computed tomography (CT) once a year to confirm the presence or absence of disease recurrence. Recurrence was identified from imaging reports or pathological examinations that were found during the review of case records.

\section{Statistical analyses}

The JMP Version 10 statistical software program (SAS Institute Inc., Cary, NC, USA) was used to conduct all analyses. Survival analysis was performed based on curves obtained using the Kaplan-Meier method. The Wilcoxon test was used for all comparisons, and $p<0.05$ was considered statistically significant.

\section{Results}

\section{Patient characteristics}

Table 1 shows the background information of all patients. The cohort included 30 males and 30 females with a mean age of 61 years (range: $25-82$ years). Moreover, the mean duration of the postoperative follow-up period was 81 months; only deaths caused by the primary disease were considered cases of mortality in this study.

\section{Surgical treatment and perioperative period}

Median sternotomy, lateral thoracotomy, the clamshell approach, and the complete thoracoscopic approach were employed in 39, one, five, and 15 patients, respectively. Additionally, 17 patients underwent extended thymectomy, while 43 underwent thymomectomy (Table 1).

Additional combined resection of adjacent organs was performed in eight patients; of these patients, six, four, one, and one underwent resection of the lung, pericardium, superior vena cava, and diaphragm, respectively. No perioperative mortality was observed, but 10 patients (16.7\%) developed postoperative complications including myasthenic crisis $(n=2)$, Horner's syndrome $(n=1)$, chylothorax $(n=1)$, respiratory failure $(n=2)$, phrenic nerve palsy $(n=3)$, and postoperative failure of the sternal closure $(n=1)$.

\section{Stage classification, therapeutic modalities, and patient prognoses}

Among the 60 patients with thymomas, 47, four, three, four, and two had tumors of stages I, II, III, IVa, and IVb, respectively (Table 1 ). The overall fiveyear survival and recurrence-free survival (RFS) rates were 96 and 86\%, respectively. Among patients with stage I, II, and III thymomas, no cases of mortality were observed during the follow-up period. The fiveyear survival rates of those with stage IVa and IVb thymomas were 100 and $0 \%$, respectively (Fig. 1a). Although the five-year survival rate of patients with stage IVa thymomas was $100 \%$, one of the four patients died of intrathoracic disseminated recurrence 123 months after surgery, while two patients with stage IVb tumors died of pleural disseminated recurrence 21 and 42 months after surgery, respectively. Meanwhile, the five-year RFS rates in stage I, II, III, IVa, and IVb tumors were 100, 75, 67, and 0\%, respectively (Fig. 1b). Patients with stage I or II tumors and III or IV tumors demonstrated five-year RFS rates of 100 and $78 \%$, respectively; therefore, stage III and IV thymomas were associated with a significantly poorer prognosis $(p<0.001)$ (Table 2$)$. The five-year survival rate among the patients who underwent incomplete resection (71\%) was significantly lower than that among those who underwent complete resection $(100 \%)$, indicating a poorer prognosis in the latter group $(p<0.001)$ (Fig. 2).

Prognostic evaluation based on the operative procedure Prognosis and recurrence-free survival were evaluated according to the differences between the surgical methods of thymectomy and extended thymectomy. The 5-year overall survival for thymectomy and extended thymectomy were 100 and 95\%, respectively, and recurrence-free survival rates were 100 and $80 \%$, respectively. Therefore, extended thymectomy tended to be associated with better prognoses in this study (Fig. 3).

\section{Prognostic evaluation based on the WHO classification}

According to the histological type (WHO classification), the cohort included six, 14, 11, 22, and seven thymomas of types $\mathrm{A}, \mathrm{AB}, \mathrm{B} 1, \mathrm{~B} 2$, and $\mathrm{B} 3$, respectively. Additionally, the five-year survival rates for types $\mathrm{A}, \mathrm{AB}, \mathrm{B} 1, \mathrm{~B} 2$, and $\mathrm{B} 3$ were $100,100,86,100$, and $86 \%$, respectively (Fig. $4 \mathrm{a}$ ). The corresponding five-year RFS rates were $100,91,91,81$, and $71 \%$, respectively (Fig. 4b).

\section{Autoimmune complications of thymomas}

The autoimmune complications of thymomas included myasthenia gravis, pure red cell aplasia, and lichen 
Table 1 Patient characteristics

\section{Characteristics}

Age (years)

Mean \pm SD

$61 \pm 14.9$

Range

Sex, $\mathrm{n}(\%)$

Male

30(50)

Female

30(50)

Masaoka stage, n (\%)

$47(78)$

III

IVa

$\mathrm{IVb}$

TNM stage, $\mathrm{n}(\%)$

$\|$

Illa

IIIb

IVa

5(8)

$\mathrm{IVb}$

Thymoma-related syndrome, n(\%

Myasthenia gravis

Pure Red Cell Aplasia

Lichen planus

Histological type, n(\%)

A

$A B$

14(23)

B1

$11(18)$

B2

22(37)

B3

$7(12)$

Tumor size $(\mathrm{cm})$

Mean \pm SD

$5.4 \pm 2.2$

Range

$1.1-10$

Operative approach, $\mathrm{n}(\%)$

Median sternotomy

39(65)

Lateral incision

$1(2)$

Clamshell incision

Video assisted thoracoscopic surgery

Operative procedure, $\mathrm{n}(\%)$

Extended thymectomy

Thymomectomy

Operative time (min)

Mean \pm SD

$184 \pm 79$

Range

40-362

Blood loss (g) 
Table 1 Patient characteristics (Continued)

\begin{tabular}{|c|c|}
\hline \multicolumn{2}{|l|}{ Characteristics } \\
\hline Mean \pm SD & $94 \pm 78$ \\
\hline Range & $1-360$ \\
\hline \multicolumn{2}{|c|}{ Postoperative treatment, $\mathrm{n}(\%)$} \\
\hline Radiotherapy & $12(20)$ \\
\hline Chemotherapy & $4(7)$ \\
\hline \multicolumn{2}{|l|}{ Resection status, $\mathrm{n}(\%)$} \\
\hline Complete resection & $53(88)$ \\
\hline Incomplete resection & $7(12)$ \\
\hline \multicolumn{2}{|l|}{ Initial relapse site (cases) } \\
\hline Pleural dissemination & 6 \\
\hline Pulmonary metastasis & 1 \\
\hline Local & 1 \\
\hline \multicolumn{2}{|c|}{ Treatment for recurrence (cases)(overlap) } \\
\hline Surgery & 1 \\
\hline \multicolumn{2}{|l|}{ Chemotherapy } \\
\hline \multicolumn{2}{|l|}{ protocol } \\
\hline ADOC & 2 \\
\hline CBDCA+PTX & 1 \\
\hline Cisplatin + Etoposide & 1 \\
\hline Radiation & 4 \\
\hline
\end{tabular}

ADOC Adriamycin + cisplatin + vincristine + cyclophosphamide, CBDCA carboplatin, PTX paclitaxel, SD standard deviation, TNM tumor, node, metastasis

planus in 10, one, and one case(s), respectively. Overall, autoimmune complications were observed in one (17\%), one (7\%), four (36\%), seven (31\%), and zero $(0 \%)$ cases with types $\mathrm{A}, \mathrm{AB}, \mathrm{B} 1, \mathrm{~B} 2$, and $\mathrm{B} 3$ tumors, respectively. The presence of autoimmune complications was significantly higher among patients with thymomas of types B1 and B2. Myasthenia gravis did not affect the prognosis of patients with thymomas (Table 2).
Treatment for recurrence and postoperative prophylactic treatment

Overall, six, one, and one patient(s) developed pleural dissemination, local mediastinal lesions, and lung metastasis during initial recurrence, respectively; thus, pleural dissemination was the most common postoperative complication. Surgical resection for pleural dissemination was performed in one recurrent case.
A

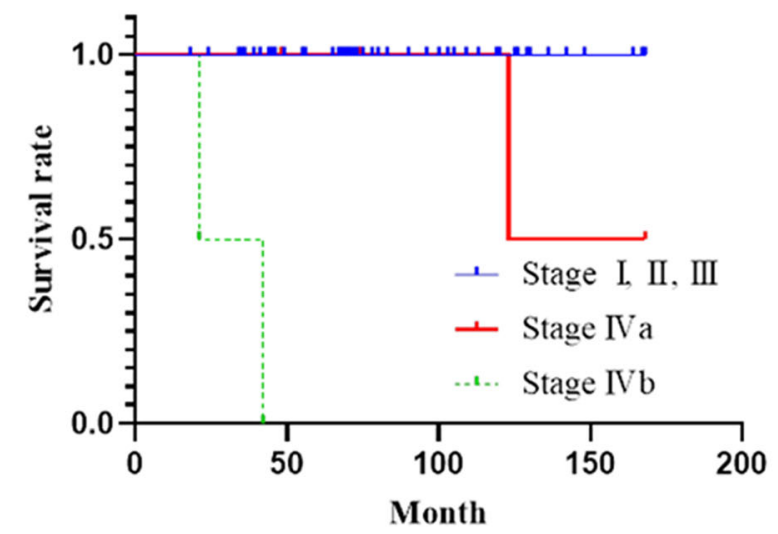

B

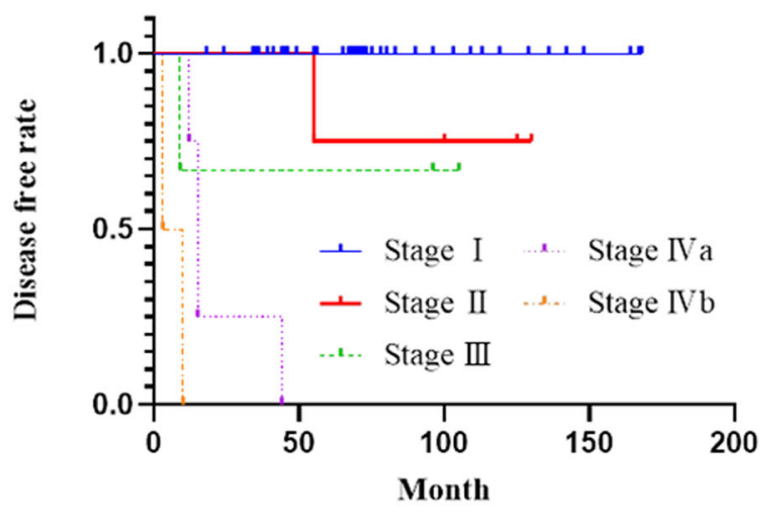

Fig. 1 Survival and recurrence-free survival curves according to the Masaoka classification. a Survival curves. b Recurrence-free survival curves 
Table 2 Univariate analysis of prognostic factors

\begin{tabular}{|c|c|c|c|}
\hline Variables & $n=60$ & Five-year survival (\%) & $P$ \\
\hline \multicolumn{4}{|l|}{ Sex } \\
\hline Male & 30 & 93 & \multirow[t]{2}{*}{0.225} \\
\hline Female & 30 & 100 & \\
\hline \multicolumn{4}{|l|}{ Age (years) } \\
\hline$<50$ & 15 & 100 & \multirow[t]{2}{*}{0.376} \\
\hline$\geqq 50$ & 45 & 95 & \\
\hline \multicolumn{4}{|l|}{ Masaoka stage, n (\%) } \\
\hline$|-| \mid$ & 51 & 100 & \multirow[t]{2}{*}{$<0.001$} \\
\hline III-IV & 9 & 78 & \\
\hline \multicolumn{4}{|l|}{ Histological type } \\
\hline$A-B 2$ & 52 & 98 & \multirow[t]{2}{*}{0.074} \\
\hline B3 & 8 & 86 & \\
\hline \multicolumn{4}{|l|}{ Myasthenia gravis } \\
\hline present & 11 & 100 & \multirow[t]{2}{*}{0.478} \\
\hline absent & 49 & 96 & \\
\hline \multicolumn{4}{|l|}{ Resection status } \\
\hline Complete resection & 53 & 100 & \multirow[t]{2}{*}{$<0.001$} \\
\hline Incomplete resection & 7 & 71 & \\
\hline \multicolumn{4}{|c|}{ Recurrent-free interval (years) } \\
\hline$<3$ & 6 & 83 & \multirow[t]{2}{*}{0.307} \\
\hline$\geqq 3$ & 2 & 100 & \\
\hline
\end{tabular}

The most frequently used chemotherapeutic regimen for the treatment of recurrence was adriamycin + cisplatin + vincristine + cyclophosphamide (ADOC), followed by carboplatin (CBDCA) + paclitaxel (PTX) and cisplatin + etoposide, respectively. After undergoing initial surgery for the primary lesion, three patients received prophylactic ADOC, while one received CBDCA + PTX chemotherapy.

Post-recurrence radiotherapy was administered to four cases with pleural dissemination, while three (6\%), two

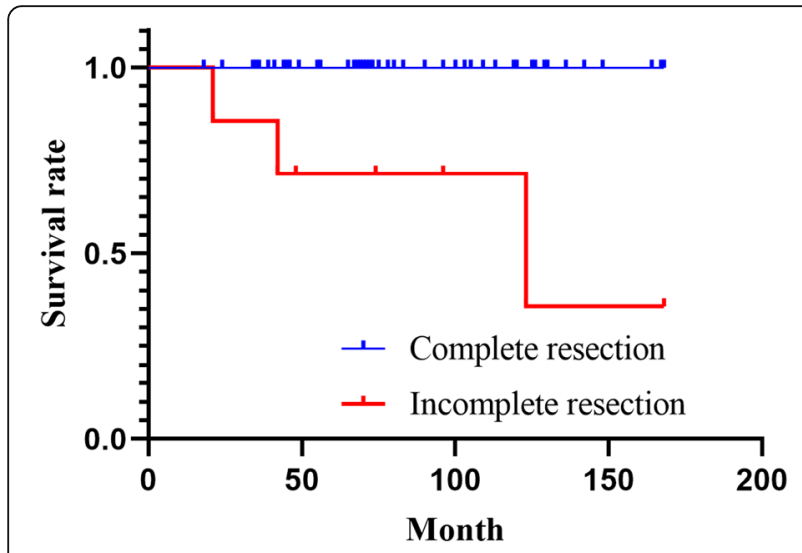

Fig. 2 Survival curves according to the resection status
(50\%), two (67\%), and five (83\%) patients with stages I, II, III, and IV thymomas received postoperative prophylactic radiotherapy, respectively. One patient with stage IV thymoma refused postoperative prophylactic radiotherapy.

\section{Prognostic evaluation based on the recurrence-free period}

The recurrence-free period was less than 3 years and 3 years or more in six and two recurrent cases, respectively. The corresponding five-year RFS rates were 83 and $100 \%$, respectively, indicating a poorer prognosis in patients with a recurrence-free period of less than 3 years, compared to 3 years or more (Table 2, Fig. 5).

\section{Discussion}

The most effective surgical modalities or approaches for stage I and II tumors remain controversial. Total thymectomy is generally performed during the removal of the tumor; however, the removal of only the tumor or partial thymectomy during tumor removal has also been explored. Because even a small tumor can lead to intrathymic metastasis and multiple thymomas, it has been argued that total thymectomy should always be considered [1]. The roles of the thymic tissues in adults remain largely unclear; therefore, further investigations are necessary to determine they should be preserved. In the presence of autoimmune complications, such as myasthenia gravis, extended thymectomy, including the surrounding adipose tissue, should be considered. Myasthenia gravis may also develop after total thymectomy; therefore, the thymus may play a partial role in autoimmune diseases. In the present cohort, one patient who had undergone thymomectomy and who had type-B2 thymoma (according to the WHO classification) developed myasthenia gravis 2 years after surgery.

Median sternotomy has been reported as the most common surgical approach; however, thoracoscopic resection has also been adopted by many institutions in recent years. Larger tumors carry a risk of pleural dissemination, even after surgery [2]; therefore, surgical modalities should be selected carefully.

In this study, the overall survival and relapse-free survival of patients who underwent thymomectomy were not significantly different from those of the patients who underwent extended thymectomy (overall survival and relapse-free survival, $p=0.326$ and $p=0.0649$, respectively). Extended thymectomy tended to be associated with better prognoses. Moreover, a prior study comparing thymectomy and thymomectomy reported that the former typically presented with a higher recurrence rate, particularly local recurrence, than the latter [3]. Therefore, our results appeared to be similar to these findings. 


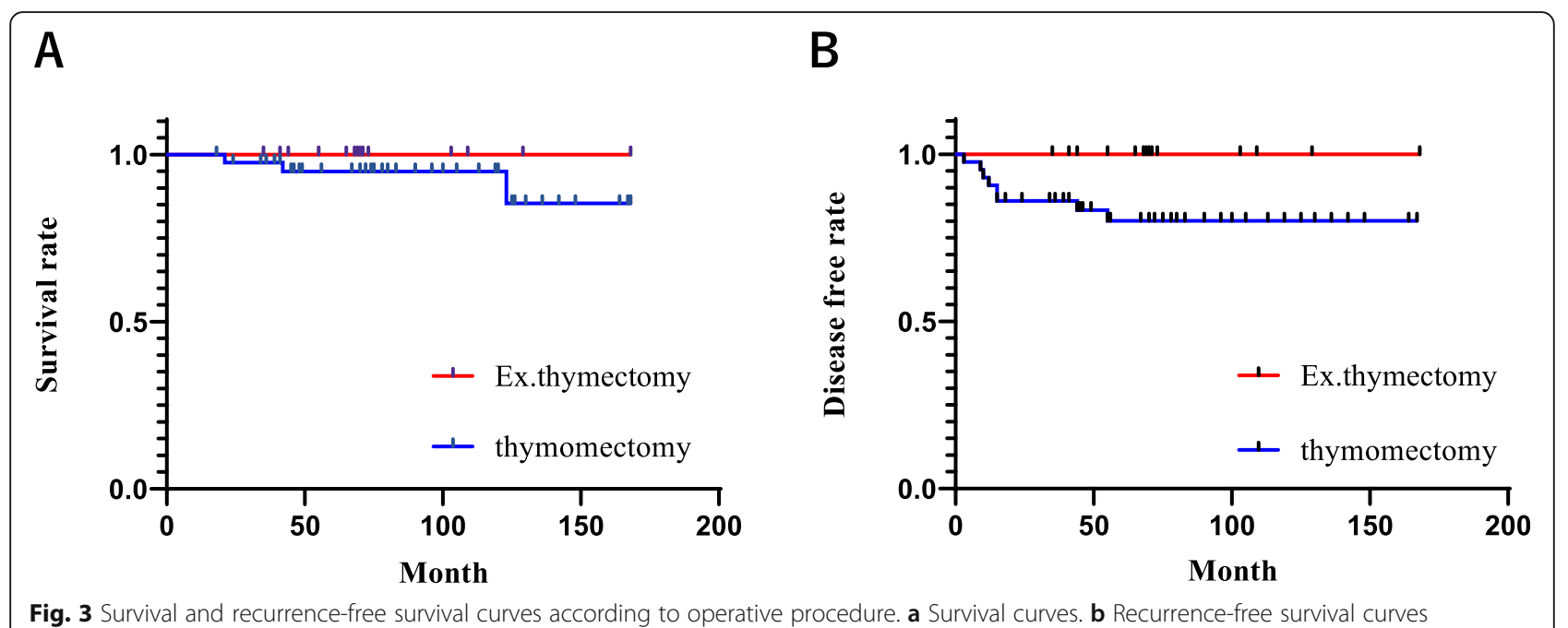

In thymomas, the degree of malignancy varies greatly depending on the pathological condition. Type $\mathrm{A}, \mathrm{AB}$, and $\mathrm{B} 1$ thymomas (according to the WHO classification) are often cured by total resection, while types B2 and B3 are invasive and usually highly advanced by the time of detection, leading to significantly high rates of postoperative recurrence [4]. Among eight cases with recurrence in this study, six (75\%) and seven (88\%) tumors were of WHO types B2 and B3 and Masaoka stages III or IV, respectively. Separately, one patient with stage II thymoma who had undergone median sternotomy thymectomy for a tumor (diameter of $7 \mathrm{~cm}$ ) experienced recurrence. This patient later received radiotherapy for the disseminated lesion and is surviving without any further disease recurrence 5 years after their initial relapse.

The most significant predictive factor for poor prognosis in thymoma is incomplete resection [5]. In this study, the five-year survival rate among patients with incomplete resection was $71 \%$; the rate was $100 \%$ for those with complete resection. Therefore, a significantly poorer prognosis was observed in the former group. A previous report indicated that the duration until recurrence is an independent prognostic factor of prognosis [6], and the findings in the present study were consistent with the previous report.

Previous studies have indicated that chemotherapeutic regimens administered for postoperative recurrence are usually used concomitantly with radiotherapy and include adriamycin, cisplatin, and vincristine. Other effective agents include taxanes and etoposide [7]. The application of regimens, such as anticancer drugs with prednisolone and steroid pulse therapy, has also been considered [8]. In the present study, one patient with stage IVa, type B2 thymoma received steroid pulse

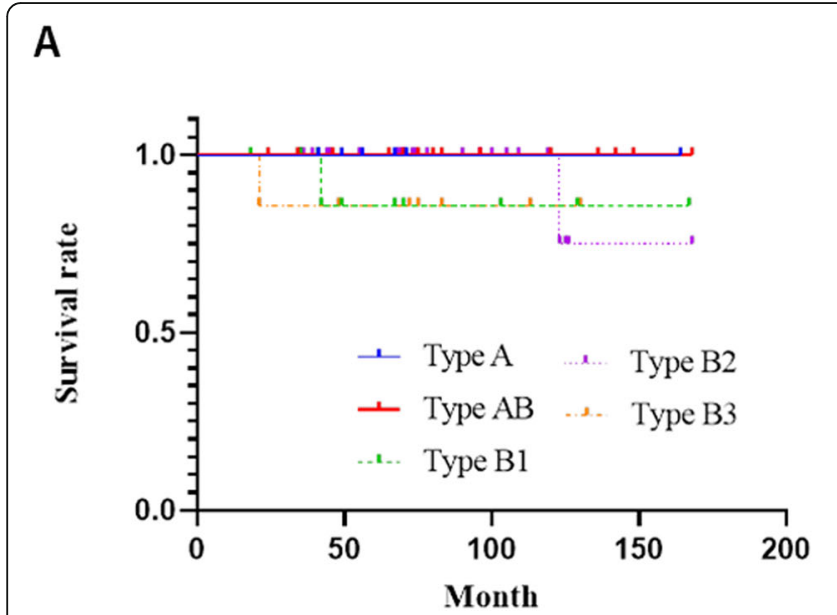

B

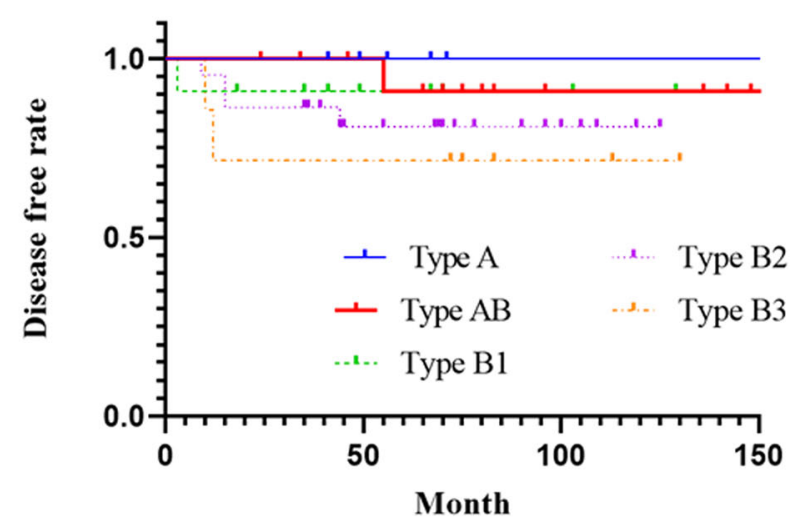

Fig. 4 Survival and recurrence-free survival curves according to the World Health Organization classification. a Survival curves. b Recurrence-free survival curves 


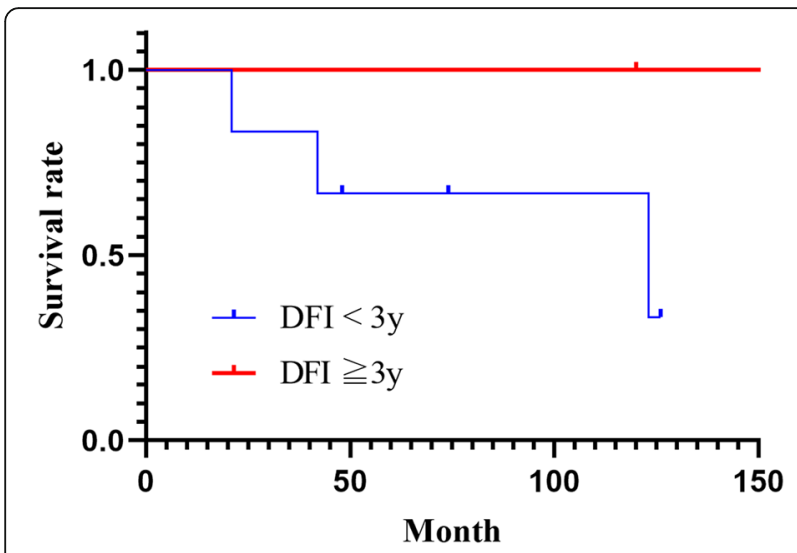

Fig. 5 Survival curves according to disease-free intervals. DFI, disease-free interval

therapy for a postoperative recurrence, with subsequent successful shrinkage of the recurrent lesion. Type $A B$, $\mathrm{B} 1$, and $\mathrm{B} 2$ thymomas contain abundant immature $\mathrm{T}$ cells with certain differentiation tendencies; additionally, thymoma epithelial cells express steroid receptors [9]. Therefore, these tumors are amenable to the effects of steroids.

Tumors in stages I and II are usually completely resectable, while postoperative radiotherapy is required only in cases with incomplete resection or suspected involvement of the surgical margin. In stage III, postoperative radiotherapy is recommended in cases with a high risk of local recurrence due to incomplete resection and other factors. However, the efficacy of postoperative radiotherapy has not been verified in patients undergoing complete resection $[10,11]$. Because recurrence is more common in the pleura and other distant regions outside the irradiated field than in the mediastinum, research has shown that radiotherapy does not improve survival following complete resection [12]. After incomplete resection, postoperative radiotherapy significantly reduced the frequency of intramediastinal recurrences and improved local control; however, due to the high frequency of pleural recurrences outside of the irradiated field [10], the overall survival is generally not influenced [13]. Consequently, radiotherapy applied to the mediastinum after complete resection of stage IV tumors effectively controls mediastinal recurrences, but does not alter overall survival. Therefore, the selection of therapeutic modalities should be individualized. Since postoperative radiotherapy is beneficial for controlling local recurrence, it should be considered for thymomas of stage III or higher; further evaluation is required to determine its efficacy regarding stage II tumors. Despite being performed at a single center, the present study evaluated individual cases in detail and, therefore, provides reliable data for subsequent research in the field of thymomas.
This study has several limitations, which include the fact that it was conducted at a single institution, it had a relatively small sample size, and it was a retrospective study. We aim to perform additional investigations by expanding the research to other institutions.

\section{Conclusions}

The findings of this study show that complete resection and the Masaoka pathological stage may be significant factors for determining the prognosis of patients with thymomas. Larger, multicenter prospective studies are warranted to confirm our findings.

\section{Abbreviations}

ADOC: Adriamycin + cisplatin + vincristine + cyclophosphamide; CBDCA: Carboplatin; PTX: Paclitaxel; RFS: Recurrence-free survival; WHO: World Health Organization

\section{Acknowledgments}

Not applicable.

\section{Authors' contributions}

SK and IS were involved in the design and drafting of the study and also wrote and revised the manuscript. YS and $\mathrm{HO}$ were involved in revising the manuscript critically for important intellectual content. All authors have read and approved the final manuscript.

\section{Funding}

There was no source of funding for this study.

\section{Availability of data and materials}

The datasets generated and/or analyzed during the current study are not publicly available due to the use of internal records of patient data and the established privacy policy but are available from the corresponding author upon reasonable request.

\section{Ethics approval and consent to participate}

The study was approved by our institutional review board (Iwate Prefectural Central Hospital), which waived the requirement for individual patient consent because only routine patient data were used for this retrospective analysis. All experiments were performed in accordance with relevant guidelines and regulations.

Consent for publication

Not applicable.

\section{Competing interests}

The authors declare that they have no competing interests.

Received: 25 August 2020 Accepted: 10 December 2020

Published online: 07 January 2021

\section{References}

1. Kawaguchi K, Usami N, Uchiyama M, Ito S, Yasuda A, Yokoi K. Triple thymoma with different histologic types. J Thorac Cardiovasc Surg. 2007; 133:826-7.

2. Kimura $T$, Inoue M, Kadota $Y$, Shiono H, Shintani $Y$, Nakagiri T, et al. The oncological feasibility and limitations of video-assisted thoracoscopic thymectomy for early-stage thymomas. Eur J Cardiothorac Surg. 2013;44: e214-8.

3. Nakagawa K, Yokoi K, Nakajima J, Tanaka F, Maniwa Y, Suzuki M, Nagayasu T, Asamura H. Is Thymomectomy alone appropriate for stage I (T1NOM0) thymoma? Results of a propensity-score analysis. Ann Thorac Surg. 2016; 101:520-6.

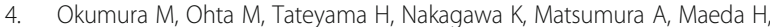
et al. The World Health Organization histologic classification system reflects the oncologic behavior of thymoma: a clinical study of 273 patients. Cancer 2002;94:624-32. 
5. Nakagawa K, Asamura H, Matsuno Y, Suzuki K, Kondo H, Maeshima A, et al. Thymoma: a clinicopathologic study based on the new World Health Organization classification. J Thorac Cardiovasc Surg. 2003;126:1134-40.

6. Mizuno T, Okumura M, Asamura H, Yoshida K, Niwa H, Kondo K, et al. Surgical management of recurrent thymic epithelial tumors: a retrospective analysis based on the Japanese nationwide database. J Thorac Oncol. 2015; 10:199-205.

7. Schmitt J, Loehrer PJ Sr. The role of chemotherapy in advanced thymoma. J Thorac Oncol. 2010;5:S357-60.

8. Kobayashi Y, Fujii Y, Yano M, Sasaki H, Yukiue H, Haneda H, et al. Preoperative steroid pulse therapy for invasive thymoma: clinical experience and mechanism of action. Cancer. 2006;106:1901-7.

9. Funakoshi Y, Shiono H, Inoue M, Kadota Y, Ohta M, Matsuda H, et al. Glucocorticoids induce G1 cell cycle arrest in human neoplastic thymic epithelial cells. J Cancer Res Clin Oncol. 2005;131:314-22.

10. Detterbeck FC, Parsons AM. Thymic tumors. Ann Thorac Surg. 2004;77: 1860-9.

11. Kondo K, Monden Y. Therapy for thymic epithelial tumors: a clinical study of 1,320 patients from Japan. Ann Thorac Surg. 2003;76:878-84.

12. Utsumi $\mathrm{T}$, Shiono $\mathrm{H}$, Kadota $\mathrm{Y}$, Matsumura $\mathrm{A}$, Maeda $\mathrm{H}$, Ohta $\mathrm{M}$, et al. Postoperative radiation therapy after complete resection of thymoma has little impact on survival. Cancer. 2009:115:5413-20.

13. Weksler B, Shende M, Nason KS, Gallagher A, Ferson PF, Pennathur A. The role of adjuvant radiation therapy for resected stage III thymoma: a population-based study. Ann Thorac Surg. 2012;93:1822-8.

\section{Publisher's Note}

Springer Nature remains neutral with regard to jurisdictional claims in published maps and institutional affiliations.

Ready to submit your research? Choose BMC and benefit from:

- fast, convenient online submission

- thorough peer review by experienced researchers in your field

- rapid publication on acceptance

- support for research data, including large and complex data types

- gold Open Access which fosters wider collaboration and increased citations

- maximum visibility for your research: over $100 \mathrm{M}$ website views per year

At BMC, research is always in progress.

Learn more biomedcentral.com/submissions 